\title{
Experimental Study on Sedimentary Rock's Dynamic Characteristics under Creep State Using a New Type of Testing Equipment
}

\author{
Wanpeng Huang, ${ }^{1,2}$ Wenbin Xing, ${ }^{2}$ Shaojie Chen, ${ }^{1,2}$ Yang Liu, ${ }^{3}$ and Kai Wu ${ }^{2}$ \\ ${ }^{1}$ State Key Laboratory of Mining Disaster Prevention and Control, Shandong University of Science and Technology, \\ Qingdao 266590, China \\ ${ }^{2}$ College of Mining and Safety Engineering, Shandong University of Science and Technology, Qingdao 266590, China \\ ${ }^{3}$ College of Mechanical and Electronic Engineering, Shandong University of Science and Technology, Qingdao 266590, China
}

Correspondence should be addressed to Wanpeng Huang; hwp20033@sdust.edu.cn and Wenbin Xing; 913231434@qq.com

Received 29 June 2017; Revised 25 September 2017; Accepted 1 October 2017; Published 25 October 2017

Academic Editor: Michael J. Schütze

\begin{abstract}
Copyright ( 2017 Wanpeng Huang et al. This is an open access article distributed under the Creative Commons Attribution License, which permits unrestricted use, distribution, and reproduction in any medium, provided the original work is properly cited.

Under high stress, rock in the creep state is vulnerable to external impact load, causing the irreversible perturbation deformation of rock or even sudden failure. To explore the dynamic characteristics of sedimentary rock in the creep state, a siltstone specimen was experimentally studied using a new type of experimental system for rock creep perturbation. Compared to the currently available equipment for studying rock dynamics, this new type of experimental system provides a long-term and stable high static stress to maintain the creep state of rock specimen. This is independent of power supply because it provides static stress by gravity load. Moreover, the equipment provides a dynamic impact load through the free fall of impact weights. This study shows that the perturbation deformation of sedimentary rock increased in two stages: decay phase and sustained development phase. When the static stress reached up to $\sim 85 \%$ of the rock's ultimate strength and the axial strain reached up to $80 \%$ of the ultimate failure strain, the rock became sensitive to impact load. This static stress level is basically the same as its long-term strength. With increasing impact strength, the increment curve of the rock creep perturbation deformation was transformed from the decay phase to the sustained development phase in advance, making the rock sensitive to external perturbation at a low static loading stress level.
\end{abstract}

\section{Introduction}

With increasing mining depth, coal mines face a higher in situ stress field environment. The concentrated stress caused by roadway excavation will make the force condition of the surrounding rock reach or exceed the long-term strength of rock. The rock mass shows a continuous creep state. The stability of deep roadway's surrounding rock in the creep state is very poor. Moreover, its creep deformation often lasts for several months or even years and also is easily affected by external dynamic perturbation loading. Such perturbations include the mining activities near the coal seams, blasting vibration in underground, strata fracture of roof, and impact pressure caused by rock burst [1-3]. The external perturbation will cause a sharp increase in the creep deformation amount of surrounding rock during creep and even sudden failure, resulting in a large deformable instability of deep roadway and other dynamic disaster phenomena. Therefore, studies on the dynamic response characteristics of a rock medium under impact perturbation loading in the rheological state have important theoretical and practical significance for the safe mining of deep coal mines.

Currently, experimental studies on rock dynamics are mostly based on impact experiments under the rock uniaxial or triaxial static compression using devices such as splitHopkinson pressure bar (SHPB), light gas gun, and drop hammer [4-6]. In the SHPB system, the rock specimen is clamped by two stress transmission bars. The static stress on specimen is created by a hydraulic system, and the dynamic load is created by a striker launcher to impact the stress 
transmission bars. In 1968, Kumar first tested the dynamic strength of a rock using SHPB [7]. Demirdag et al. studied the dynamic mechanical behavior of some carbonate rocks using a classical servohydraulic testing machine and an SHPB testing system [8]. Moreover, some modifications to SHPB were carried out, allowing it to be more adaptive for certain rock dynamic experiments. For example, Li et al. studied the dynamic characteristics of granite subjected to an intermediate loading rate and proposed a new testing technique involving the modification of SHPB so that the test specimen is subjected to coupled axial static prestress, axial impact loading, and optional confining pressure [913]. The static stress system of a drop weight machine is similar to SHPB. The main difference is the loading method of dynamic stress. It uses a heavy hammer that drops from a certain height to impact the piston plate. The shock wave created by the impact is transmitted to a specimen. The drop weight machine was usually used in the dynamic mechanical experiments of rock or concrete. Okubo et al. conducted large-scale penetration tests of rock samples using a wedgetype drop hammer in 1997 [14]. In the recent years, drop weight machine has been used to study the dynamic fracture characteristic of rock and relationship between the impact energy, rock strength, and so forth [15-17].

According to the above-mentioned literature analysis, the static stress loading system of the existing experimental equipment for rock dynamics is similar to the equipment used in rock experiments such as MTS. It uses a hydraulic system to provide static stress. This loading mode is stable but suffers from the fact that the stress system must be preserved using a power source. Therefore, this equipment is only suitable for the short-time experiments of rock dynamics. The rock impact experiment in the creep state belongs to the category of long-term dynamic experiment. The static loading system of the equipment should be able to provide a long-term (e.g., a few days, months, or even years) and stable high static stress to maintain the stable creep state of rocks. At the same time, the experimental system can also provide a dynamic impact load to a rock specimen to study the dynamic response of rock under creep condition. According to literature, currently, a few studies have been reported on the dynamic mechanical characteristics of rock creep disturbance, and the experimental equipment needed for this type of study is limited.

To conduct this type of studies, we independently developed a new type of experimental system for rock creep disturbance. Further, a creep perturbation experiment of hard siltstone specimens was also carried out using the new experimental system. A preliminary study on the creep perturbation deformation law of rock specimens was conducted, and the rock's antiperturbation strength (the static stress level at which the rock becomes sensitive to an impact load) was investigated, thus laying a theoretical foundation for the stability control of deep rock engineering under perturbation effect.

Based on the preliminary study, we define the mechanical phenomenon as "rock creep disturbance effect"; that is, the rock can produce the corresponding creep strain increment after the external impact load is applied. It belongs to the category of rock rheological mechanics and rock dynamics and reflects the creep deformation rule of the rock under the creep condition under the influence of an external impact load. This is a new research direction in rock creep.

\section{Experimental Equipment}

To study the dynamic characteristics of a rock in the rheological state, a new type of equipment known as a testing system for rock creep perturbation effect (RRTS) was developed. This new equipment was able to apply a long constant axial pressure to a rock specimen by gravity loads that increased to two grades. The equipment, independent of power supply, can produce long-term and stable loads on samples. It produced perturbation loads by the shock of steel rings to the upper bearing plate. It is suitable for long-term static creep tests and RRTS experiments under uniaxial and conventional triaxial conditions [18]. The testing equipment is shown in Figure 1. It consists of two parts: the testing machine and data monitoring system.

2.1. Force-Amplification Structure and Principle of Stress Loading System. The stress applied to a rock specimen originates from the gravity load of circular ring-shaped weight made of cast iron. The weights were $1 \mathrm{~kg}, 3 \mathrm{~kg}, 5 \mathrm{~kg}$, and $10 \mathrm{~kg}$. The equipment's two grades of force amplification can increase the original gravity load by 60-100 times. The first grade of force amplification is achieved by a mechanical gear transmission structure, and the second grade of force amplification is achieved by a hydraulic transmission structure.

2.1.1. First Grade of Mechanical Force Amplification. This structure (Figure 2) includes a transmitted rotary table, shaft, and transmitted gear. The edge of the rotary table had chains, and the weights were hung on the chains to impose gravity load on the rotary table. Then, the gravity load was delivered to the transmitted gear connected to a transmitted rack. Because of the size differences in the rotary table and gear, the gravity load achieves first-grade amplification.

According to moment equilibrium conditions, the force in the first grade is amplified as follows:

$$
F_{1}=\frac{R_{0}}{R_{1}} W_{0},
$$

where $F_{1}$ is the amplified force applied on the small cylinder, $W_{0}$ is the gravity load and also the total weight of weights, and $R_{0}$ and $R_{1}$ are the radii of the transmitted rotary table and gear, respectively.

2.1.2. Second Grade of Hydraulic Force Amplification. This structure (Figure 3) includes a transmitted rack, a small cylinder, a large cylinder, and an oil-transferring pipeline. Force $F_{1}$ is directly pressed on the pressure axis of the small cylinder using the transmitted rack. Then, the force is transferred to the large cylinder through the oil-transferring pipeline. The piston on the top of the large cylinder is pushed upwards to provide load to the rock specimen. Because 

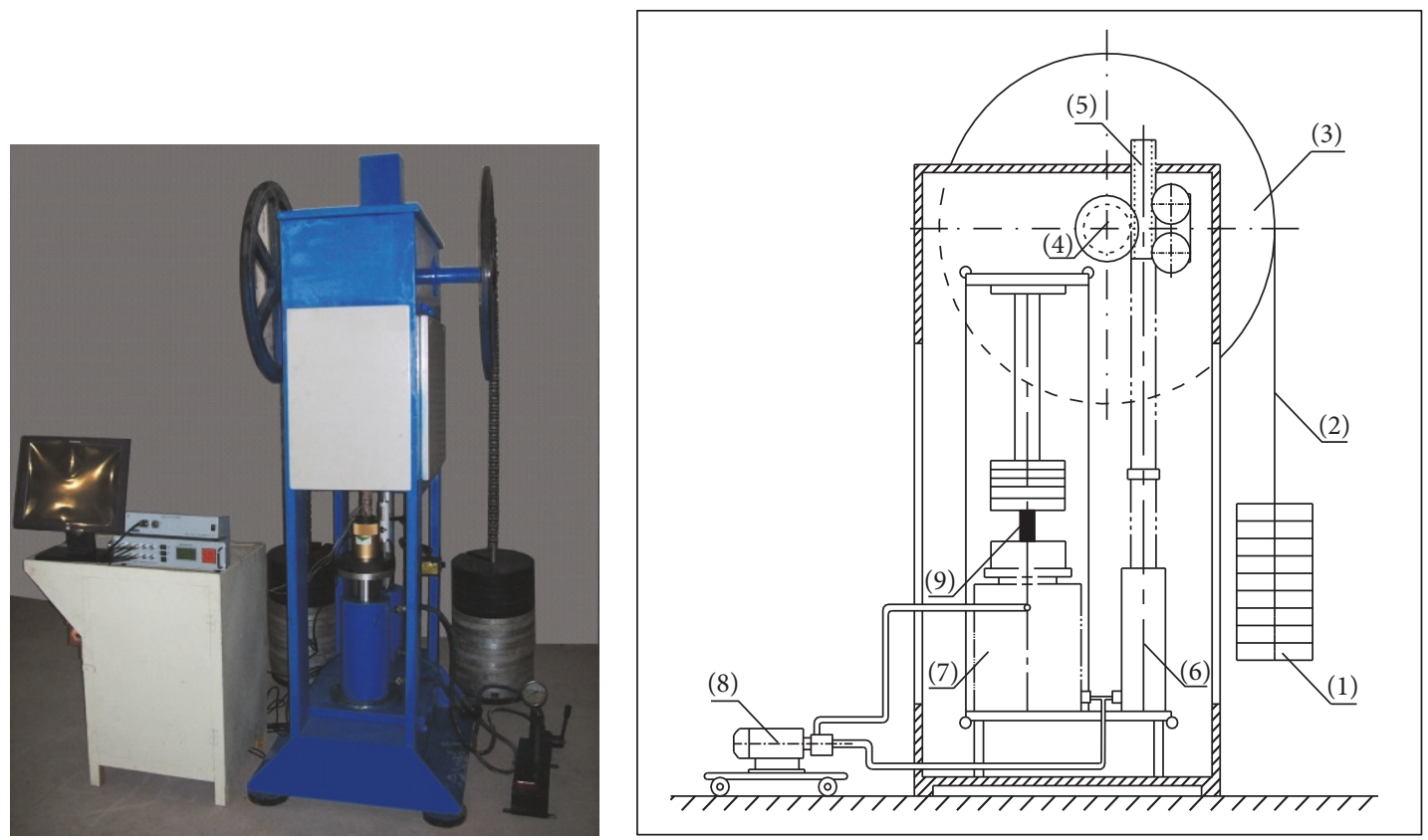
(1) Weightst
(4) Gear
7) Large cylinder
(2) Chains
(5) Rack
(8) Hydraulic pump
(3) Rotary table
(6) Small cylinder
(9) rock specimen

(a) Picture of machine

(b) Overall structure

FIGURE 1: Structure of testing equipment.

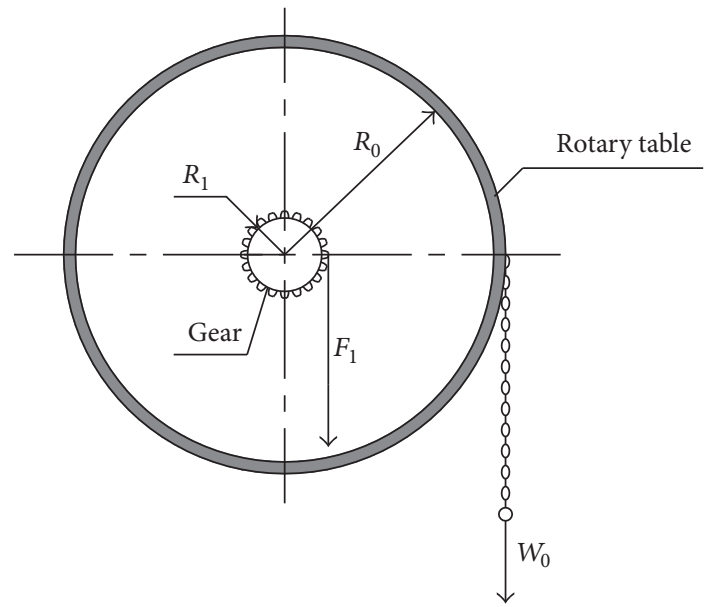

FIGURE 2: Schematic diagram of mechanical force amplification.

of the size differences of the cylinders, the load achieves second-grade amplification. According to static equilibrium conditions, the force amplified in the second grade can be expressed as follows:

$$
F_{2}=\left(\frac{\phi_{2}}{\phi_{1}}\right)^{2} \cdot F_{1}
$$

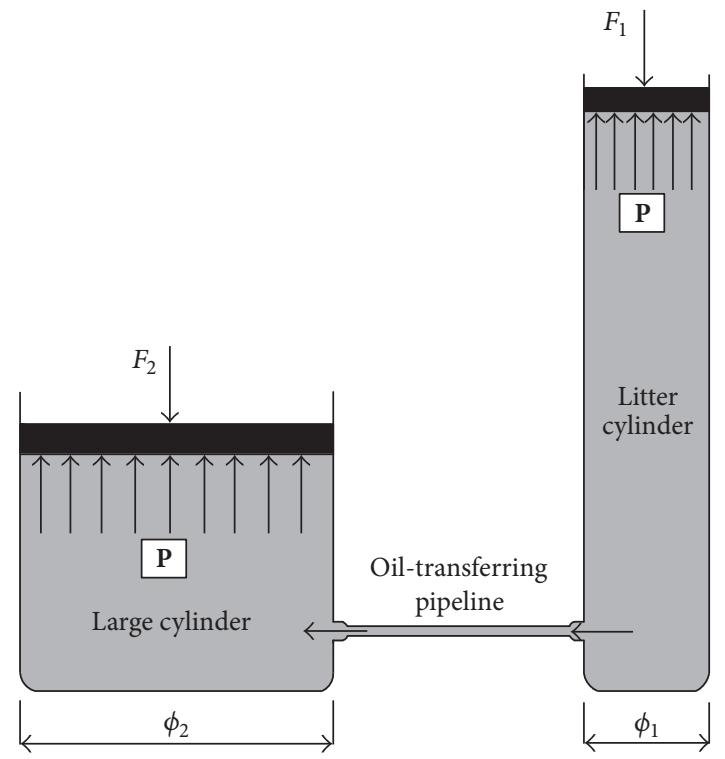

FIGURE 3: Schematic diagram of hydraulic force amplification.

where $\phi_{1}$ and $\phi_{2}$ are the diameters of the large and small cylinders, respectively, and $F_{2}$ is the force applied by the large cylinder and also the stress load on the rock specimen. 

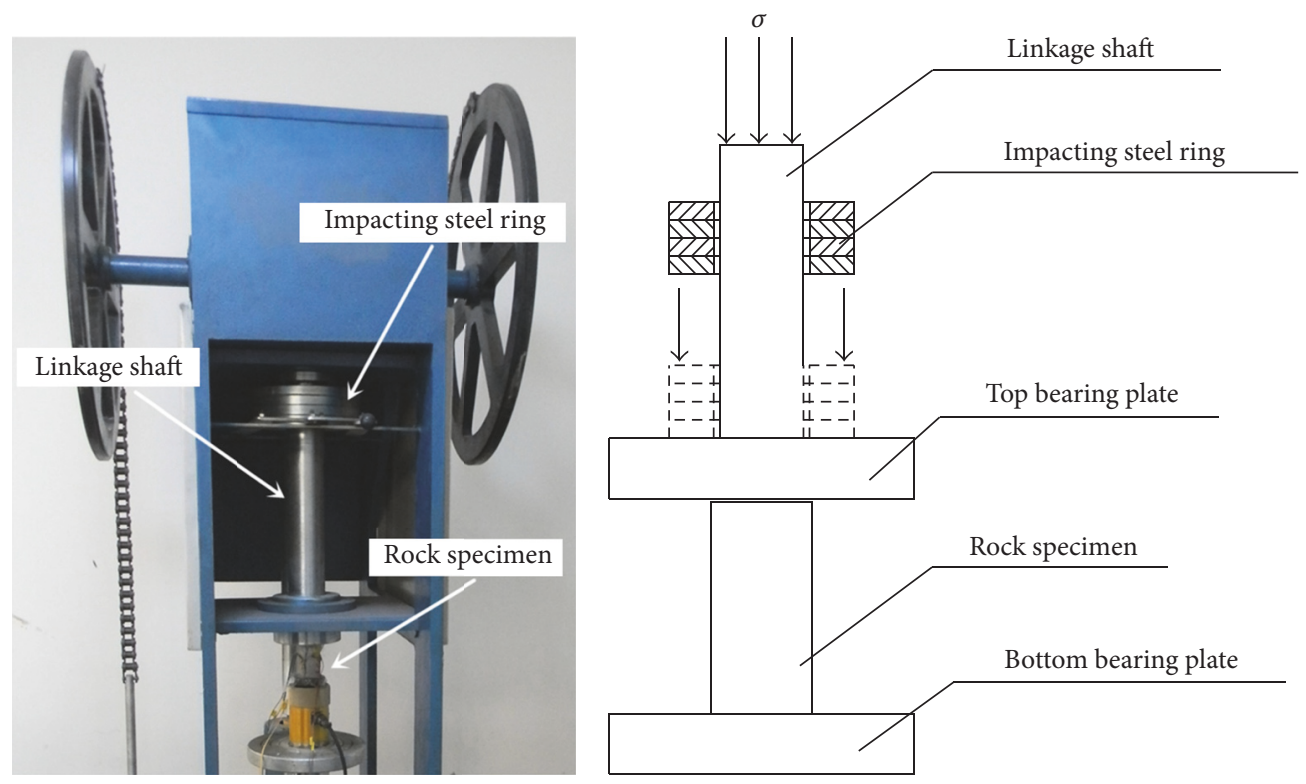

Figure 4: Application mode structure of perturbation loading.

Combining formulas (1) and (2), the stress load through the two grades of force amplification can be expressed as follows:

$$
F_{2}=\frac{R_{0}}{R_{1}}\left(\frac{\phi_{2}}{\phi_{1}}\right)^{2} W_{0} .
$$

2.2. Loading Mode of Impact Perturbation. The load infliction of the external perturbation loading occurs through the free fall of the impact weights. The weights impact the top bearing plate located on the upper part of the equipment as shown in Figure 4 . Then, the impact load can be transferred to creep rock specimen.

In the concrete method, steel-ring weights are present around the linkage of equipment's top bearing plate. Each steel ring has three different weights of $3 \mathrm{~kg}, 5 \mathrm{~kg}$, and $10 \mathrm{~kg}$. Therefore, different numbers of steel rings can be combined to different impact blocks. The impact block falls down from different relative heights of 100-400 mm, thus exerting various perturbation loads on the rock specimen. After the rock specimen's deformation is in the creep stage at a certain level of static stress, the steel rings are lifted up to a certain relative height and then allowed to fall freely. When the steel rings fall on the top bearing plate, the impact load generated is transferred to the rock specimen (Figure 4).

According to the impulse and energy theorem, if the energy loss is ignored, the geopotential energy of impact weights can be completely transformed by impact momentum to the rock specimen. Thus, the impact momentum of perturbed load imposed on rock specimen $\Delta W$ can be calculated as follows:

$$
\Delta W=F \cdot \Delta t=m \cdot v=m \sqrt{2 g h},
$$

where $F$ is the average impact force imposed on the specimen, $\mathrm{N} ; \Delta t$ is the action time period of impact force, $s ; m$ is the weight of the steel ring, $\mathrm{kg} ; v$ is the impact velocity when the steel ring drops to the bearing plate; $g$ is the acceleration of gravity: $g=9.8 \mathrm{~m} / \mathrm{s}^{2}$; and $h$ is the falling height, $\mathrm{m}$. According to theoretical calculation, the impact momenta imposed on the rock specimens of $5 \mathrm{~kg}$ and $10 \mathrm{~kg}$ in weight were $7 \mathrm{~N} \cdot \mathrm{s}$ and $14 \mathrm{~N} \cdot \mathrm{s}$, respectively.

\section{Process and Method of Experiment}

3.1. Rock Specimens. Gray-black siltstones collected from $-1200 \mathrm{~m}$ horizontal strata in the Xinwen coalfield in Shandong Province were selected as the rock specimen in the experiment. After the processing, the specimens were screened for ultrasonic testing (UT). According to the UT results, the longitudinal wave velocity of siltstone specimens was $3.48 \mathrm{~km} / \mathrm{s}$ in average, and the dynamic modulus was $30.8 \mathrm{GPa}$ in average. The crosswise and axial strain gages were stuck on specimens to measure the transverse and axial strains of rock specimens in the loading procedure. During the experiment, the JC-II load transducer was padded under the rock specimen to record the actual capacity of the load, as shown in Figure 5.

3.2. Confirmation of Long-Term Strength. This is an impact perturbation experiment in the dynamic state under creep state of the rock. According to previous studies, in the long-term rock creep experiments, the creep process can be divided into three creep stages (deceleration, stable, and accelerated creep stage). Also, the sensitivity of rock to external disturbances at different creep stages is different. The threshold stress of the rock entering the stable creep stage is defined as the rock's long-term strength. To study the dynamic response characteristics of rock to external disturbance loads in different creep stages, first the longterm strength was determined by conducting a static creep 
TABLE 1: Perturbation parameters of two impact weights.

\begin{tabular}{lccc}
\hline Perturbation weight $(\mathrm{kg})$ & Force peak $(\mathrm{N})$ & Effective impact time $(\mathrm{s})$ & Total action time $(\mathrm{s})$ \\
\hline 5 & 450 & 0.015 & 0.028 \\
10 & 960 & 0.013 & 0.03 \\
\hline
\end{tabular}

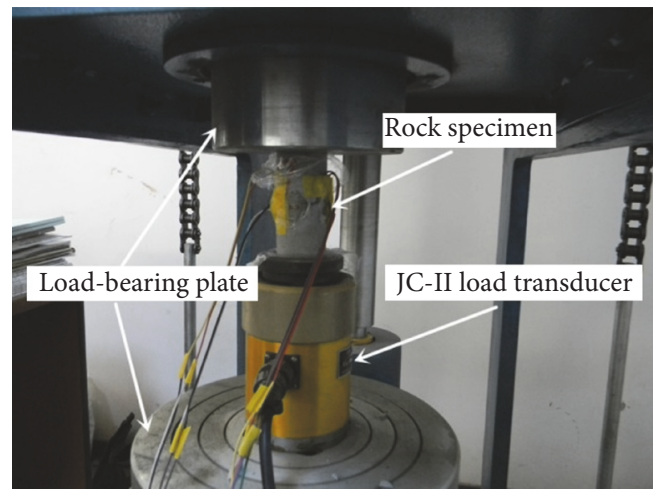

Figure 5: JC-II load transducer.

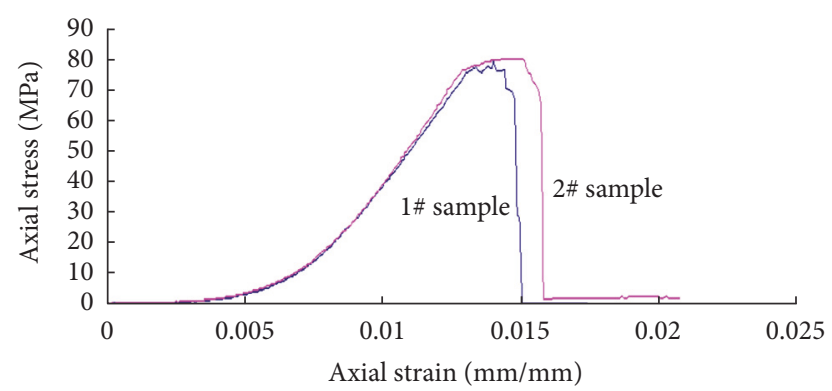

Figure 6: Stress-strain curve of sedimentary rock under uniaxial press.

experiment to estimate the capacity of static loading stress when the rocks are in the stable creep state. Then, based on the standard of long-term strength of rocks, each level of static loading stress that impacts loading was exerted.

Before the static creep test of rock, the conventional uniaxial compression experiments (short-term compression experiment and the mechanical parameters obtained are not related to time) of two rock samples were carried out using an MTS servo-controlled rock mechanics system. Furthermore, the stress-strain curves obtained for sedimentary rock are shown in Figure 6. According to the analysis of testing dates, the ultimate strength and strain of two samples are close. The ultimate strengths (the maximum stress in the case of rock failure in a short-term compression experiment) of $1 \#$ and 2\# samples were $81.17 \mathrm{MPa}$ and $82.88 \mathrm{MPa}$, respectively. The ultimate strength of sedimentary rock was about $82.03 \mathrm{MPa}$. When the ultimate strength of a rock is determined, the stress rating in the creep experiment can be determined by taking the ultimate strength as the extreme.

According to a previous experimental study on rock mechanics, under the normal uniaxial compression condition, the range of the statistics of the specific value of long-term and ultimate strengths of soft rock was about 60-80\%; for a medium and hard rock, the specific value was generally between 85 and 95\% [2, 19-23].

First, the uniaxial compressive creep test of the three specimens was carried out before starting the impact perturbation experiment. The static stress in the experiment was pushed in different levels by considering the rock's ultimate strength as the extreme. The different stages of creep curves of $3 \#$ and $4 \#$ are shown in Figure 7.

The long-term strength was confirmed using the creep transition method by fitting the obtained creep curve. This method considers the static stress level, where the rock sample's creep rate is about 0 as the rock's long-term strength [24]. As shown in Figure 7, according to the analysis of fitting to rock's creep curve, the creep rates of both samples tend to be 0 at the first two static stress levels. After the third stress level, the curve started to upturn. Furthermore, the fitting results show that the creep rate is above 0 at these stages. The result of third sample shows a similar trend. According to comprehensive analysis, the sedimentary rock's long-term strength is about $69.7-71.3 \mathrm{MPa}$. Average is $70.5 \mathrm{MPa}$. The specific rate of long-term and ultimate strength was $86 \%$.

\subsection{Experimental Method for Rock Creep Perturbation Effect.} Before starting the experiment, the impact capacities of selected weights of $5 \mathrm{~kg}$ and $10 \mathrm{~kg}$ were measured with a dropping height of $10 \mathrm{~cm}$. The vibration oscillogram of impact force (diagram $F-t$ ) obtained from the test is shown in Figure 8. According to the testing results, the total action time of impact wave was approximately $0.250 .3 \mathrm{~s}$, and the vibration wave demonstrated good integrity and transitivity. The time interval between two adjacent impacts is about $120 \mathrm{~s}$. With the short duration of each impact wave, it can be considered that the next impact wave will not influence the above impact wave, and each impact is independent. The tested impact force peak of $5 \mathrm{~kg}$ weight imposed on the rock sample was about $450 \mathrm{~N}$, and the converted amplitude of stress was about $0.23 \mathrm{MPa}$. The effective impact time $\Delta t$ (the effective time-width of impact wave) was about $0.015 \mathrm{~s}$. The impact force peak of $10 \mathrm{~kg}$ weight imposed on the rock sample was about $960 \mathrm{~N}$, and the converted amplitude of stress was about $0.49 \mathrm{MPa}$. The effective impact time $\Delta t$ was about $0.013 \mathrm{~s}$. Considering the force peak as the average action force during the effective impact time $\Delta t$, the impact momentum of each impact was about $6.75 \mathrm{~N} \cdot \mathrm{s}$ ( $5 \mathrm{~kg}$ weight) and $12.48 \mathrm{~N} \cdot \mathrm{s}$ (10 kg weight). This result is quite similar to the theoretical calculation. The perturbation parameters of the combination of two impact weights are shown in Table 1.

The rock creep perturbation experiment was carried out under different static loading stress levels, and $80 \%$ of the long-term strength of the specimen was the initial static loading stress level. The experiment was divided into six 
TABle 2: Actual static stressin each level.

\begin{tabular}{|c|c|c|c|c|c|c|}
\hline & $\begin{array}{c}\text { Stress level } \\
1\end{array}$ & $\begin{array}{l}\text { Stress level } \\
2\end{array}$ & $\begin{array}{l}\text { Stress level } \\
3\end{array}$ & $\begin{array}{l}\text { Stress level } \\
4\end{array}$ & $\begin{array}{l}\text { Stress level } \\
5\end{array}$ & $\begin{array}{c}\text { Stress level } \\
6\end{array}$ \\
\hline Load application (MPa) & 56.5 & 59.8 & 64.1 & 66.8 & 70 & 79.6 \\
\hline $\begin{array}{l}\text { Ratio to long-term } \\
\text { strength (\%) }\end{array}$ & $80.1 \%$ & $84.8 \%$ & $90.9 \%$ & $94.7 \%$ & $99.3 \%$ & $112.9 \%$ \\
\hline $\begin{array}{l}\text { Ratio to ultimate strength } \\
\text { (\%) }\end{array}$ & $68.9 \%$ & $72.9 \%$ & $78.2 \%$ & $81.5 \%$ & $85.4 \%$ & $97.1 \%$ \\
\hline Single impact load (MPa) & $0.23 / 0.49$ & $0.23 / 0.49$ & $0.23 / 0.49$ & $0.23 / 0.49$ & $0.23 / 0.49$ & $0.23 / 0.49$ \\
\hline
\end{tabular}

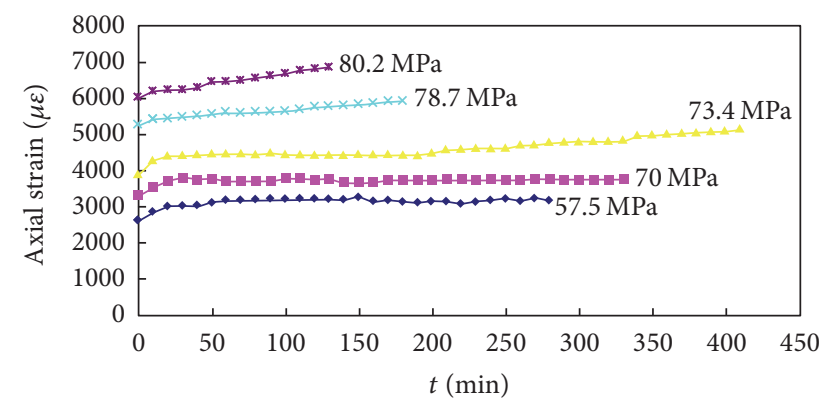

(a) 3\# sample

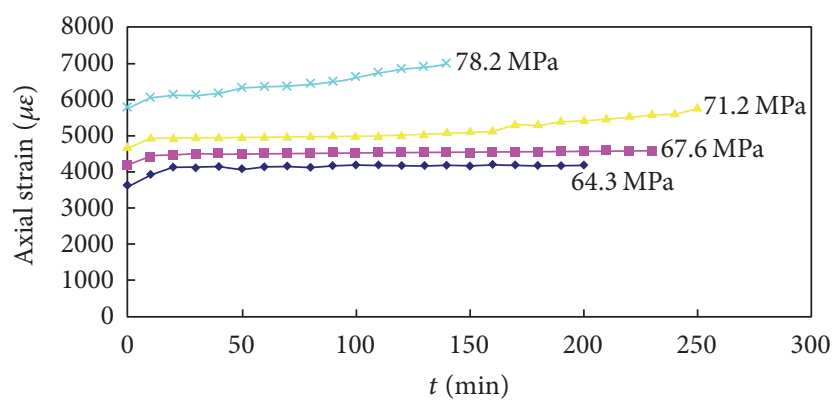

(b) 4\# sample

FIGURE 7: Different stages of creep curve of 3\# and 4\# samples.

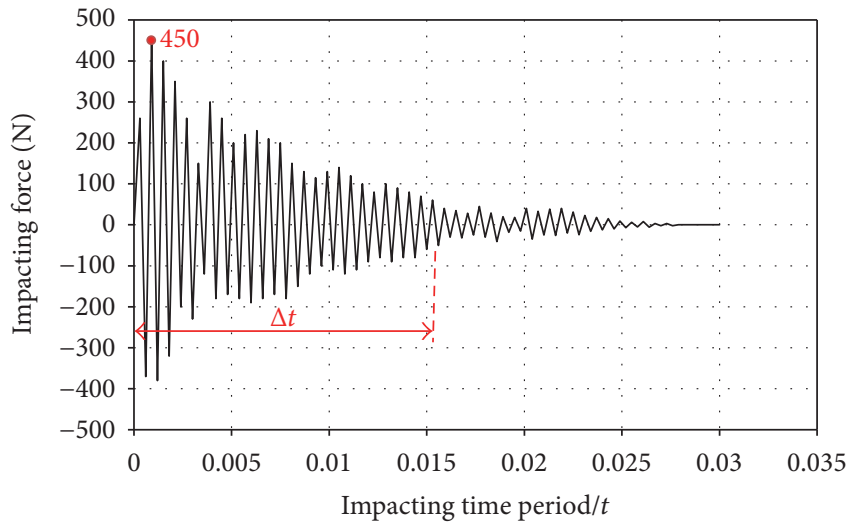

(a) Impact weight of $5 \mathrm{~kg}$

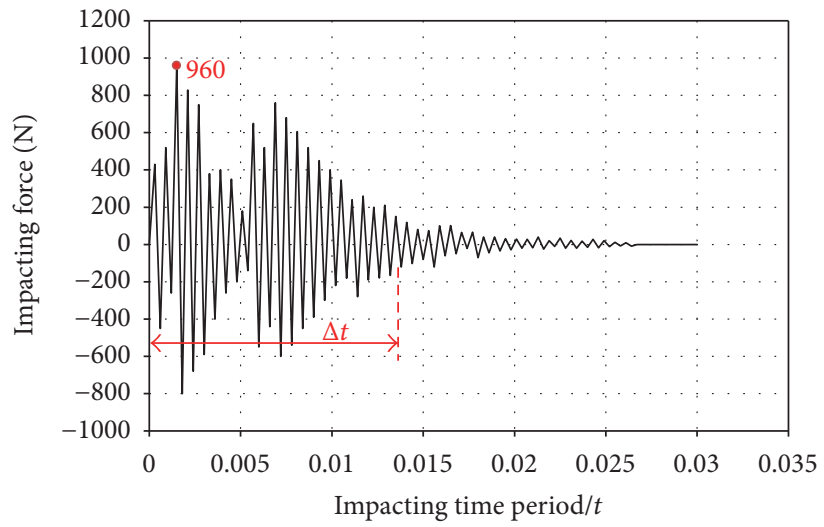

(b) Impact weight of $10 \mathrm{~kg}$

Figure 8: Vibration oscillogram of impact force (force-time diagram $F-t$ ).

levels. Taking 2\# specimen in the first group as an example, the imposed static loading stress of each level is shown in Table 2. According to previous tests, the creep deforming rate was unstable in the initial stage of every level of static load. If the static stress was maintained for $24 \mathrm{~h}$ or longer, the rock sample's creep rate became more stable. Therefore, the loading of static stress in each level lasted for about $48 \mathrm{~h}$. After the creep deformation of the rock specimen was stable, the impact perturbation experiment was started. The selected impact weights were divided into two types, that is, $5 \mathrm{~kg}$ and $10 \mathrm{~kg}$. The specimens were used to test the perturbation deformation regularity of hard siltstone specimens under different impact loadings. Then, the dynamic response of the specimens in the creep perturbation state was analyzed and summarized.

During the experiment, the continuous impact of several times was taken as one perturbation. After completing the impact for each time, the related strain amount of the specimens was recorded. The experiment was designed to impose two times of perturbation under each static stress level. Two perturbations were carried out at a time interval of $12 \mathrm{~h}$, and a total of 12 perturbations were carried out during the entire experiment (under the sixth stress level, the specimen was destroyed when the first perturbation was imposed; therefore, in fact a total of 11 perturbations were conducted). The experiment was started with multistage 
loading. First, the loading pressure reached the first level of static loading stress. Under this level of stress, the specimen creeps for $48 \mathrm{~h}$. After reaching a stable state of the amount of creep deformation, the first perturbation experiment was conducted (including several times of impact). Then, the homologous accumulative total deformations of perturbation were recorded. The day after the first perturbation, the second impact perturbation was conducted under the same static stress level, and the homologous accumulative total deformation of perturbation was recorded. After the perturbation experiment under first static stress level, the stress of the load reached the second static stress level. The third and fourth perturbation experiments were conducted after the creep was stable. In this manner, the perturbation experiments of the third and fourth static stress levels were conducted, and the accumulative total perturbation deformation was recorded.

\section{Experimental Results}

Three rock specimens were tested in each group of experiments. The results show a similar regularity. Therefore, the experimental methods and process control are accurate. Moreover, the results also prove the regulation, that is, slight divergence in the creep perturbation deformation on sedimentary rock specimen. According to the experimental data obtained for typical number 2 rock specimen in the two groups of experiments, the perturbation did not obviously affect the lateral creep deformation of rock. Therefore, only the relationship between axial cumulative disturbance deformation and impact numbers was analyzed. The initial dependent variables and cumulative disturbance deformation through various levels of static stress are shown in Table $3 ; \varepsilon_{0}$ is specimen's ultimate strain.

In the first group of experiments with an impact weight of $5 \mathrm{~kg}$, the rock specimen's ultimate strain was $6945 \mu \varepsilon$ before the rock failure at the last stress level. This is regarded as the specimen's ultimate strain $\varepsilon_{0}$. In the second group with a loading impact of $10 \mathrm{~kg}$, the ultimate strain was $6782 \mu \varepsilon$. This should be regarded as the specimen's ultimate strain $\varepsilon_{0}$ in this group. When the impact loading was $5 \mathrm{~kg}$, the increment curves between perturbation impact times $N$ and axial cumulative disturbance deformation under various stages of static stress level are shown in Figure 9. To analyze more clearly, the above curves were integrated to obtain the entire curve shown in Figure 10. Using the same method, the integrated curve of $10 \mathrm{~kg}$ impact loading was obtained as shown in Figure 11.

\section{Discussion}

5.1. Characteristic of New Equipment. The application of new equipment showed high stability and accuracy in the experimental process. First, the static stress applied to rock specimen up to $56.5-79.6 \mathrm{MPa}$ originating from the gravity load could be enlarged by the equipment's two grades of forceamplification system. That made the specimen remain in a stable creep state. Further, in the 48-hour loading process of each stress level, the static stress remained very stable with almost no reduction according to the results of JC-II load transducer. Thus, the experimental purpose of loading a long-term stable static stress was achieved. During the experiment, the static stress could be increased conveniently from a lower stress level to a higher stress level by increasing the iron weights. Second, in the dynamic impact process of experiment, each impact caused a certain amount of disturbance deformation to the rock specimen in the creep state. Further, the disturbance deformation obviously showed some regularity (Figure 7 ). This indicates that the impact energy well propagated into the interior of rock specimen and disturbed its creep deformation. Finally, during the experiment, the new equipment could be easily operated because of its simple structure. According to the analysis of experimental process and results, this new type of equipment is more suitable for studying the dynamic characteristics of a rock in the creep state compared to conventional experimental equipment.

\subsection{Characteristic Analysis of Rock Creep Perturbation Defor-} mation. The experiment results show that, under a high stress, external perturbation loading was applied to sedimentary rock during the flow deformation, also leading to an irreversible increase in perturbation deformation. This is similar to the perturbation deformation of a soft rock except that the sedimentary rock has a higher level of static stress, sensitive to outside perturbation. According to the curve analysis of the experimental data, the curve of siltstone test specimen cumulative disturbance deformation follows the same regulation, occurring through two stages.

5.2.1. Decay Stage of Cumulative Disturbance Deformation. Rock axial strain is $<80 \%$ of limit strain before the disturbance at the first four stress levels $(56.5 \mathrm{MPa}, 59.8 \mathrm{MPa}$, 64.1 MPa, and $66.8 \mathrm{MPa}$ ). With the impact of $5 \mathrm{~kg}$ weight, the dynamic load of each impact was $0.23 \mathrm{MPa}$; the impact momentum was $6.75 \mathrm{~N} \cdot \mathrm{s}$. With the impact of $10 \mathrm{~kg}$ weight, the dynamic load of each impact was $0.49 \mathrm{MPa}$; the impact momentum was 12.48 N.s. As shown in Figures 10 and 11, at static stress level $1(56.5 \mathrm{MPa})$, when impacting with $5 \mathrm{~kg}$ weight, each impact caused the corresponding disturbance deformation in the first seven impacts. The axial cumulative disturbance deformation increased rapidly with a linear growth. To the 8th impact, the cumulative impact loads reached $1.84 \mathrm{MPa}$, and the cumulative impact momenta reached $54 \mathrm{~N} \cdot \mathrm{s}$. The cumulative disturbance deformation started to decline and nearly approached zero; that is, several posterior impacts did not increase the axial deformation any longer, and the rock started to impact hardening. With the impact of $10 \mathrm{~kg}$, even if the impact loads and momentum increased, the disturbance deformation still no longer increased to the seventh impact (the cumulative impact loads reached $3.43 \mathrm{MPa}$, and the cumulative impact momenta reached $87.36 \mathrm{~N} \cdot \mathrm{s})$. Then, under the static stress levels 2, 3, and $4(59.8 \mathrm{MPa}, 64.1 \mathrm{MPa}$, and $66.8 \mathrm{MPa})$, the variation in the cumulative disturbance deformation showed a similar regularity. This proves that even when increasing the impact strength, the cumulative disturbance deformation did not 


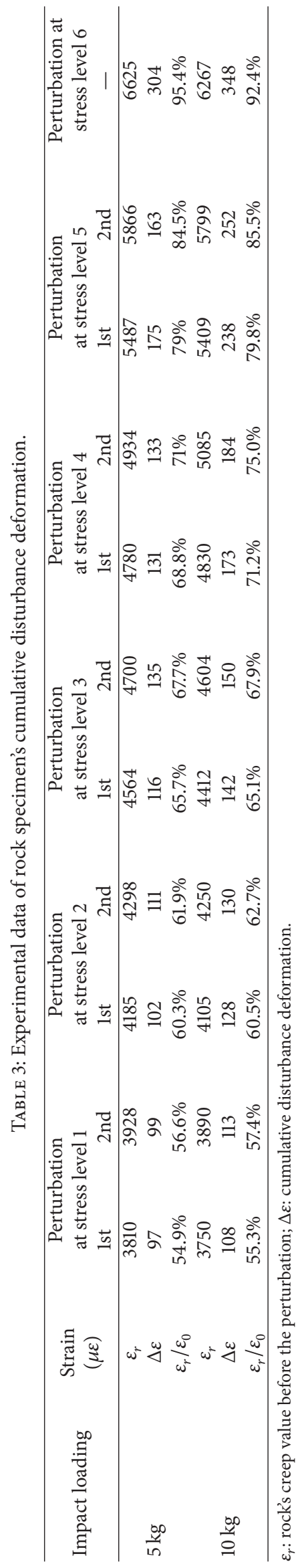




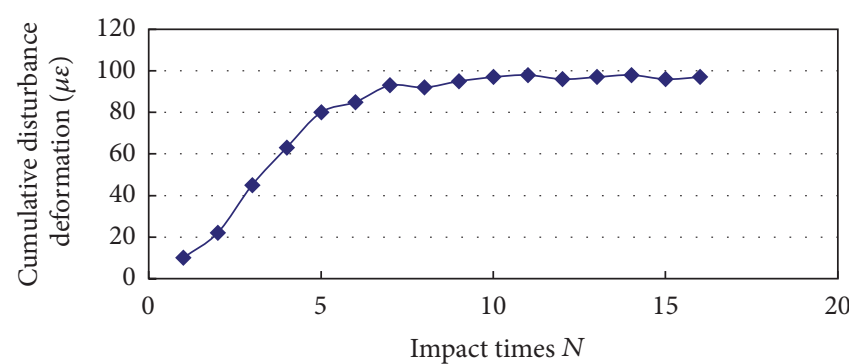

(a) First perturbation

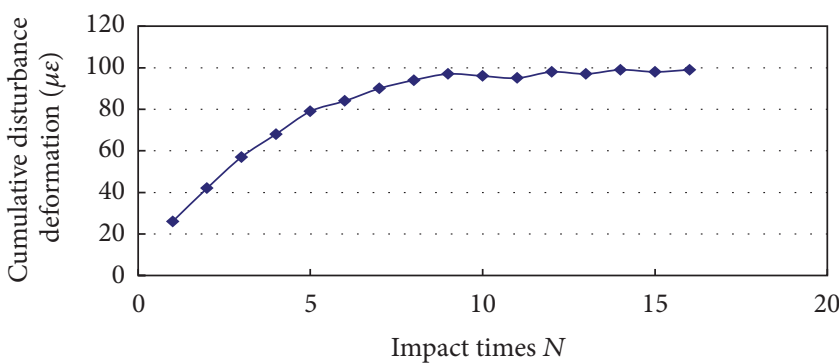

(b) Second perturbation

(1) Level 1 of static stress

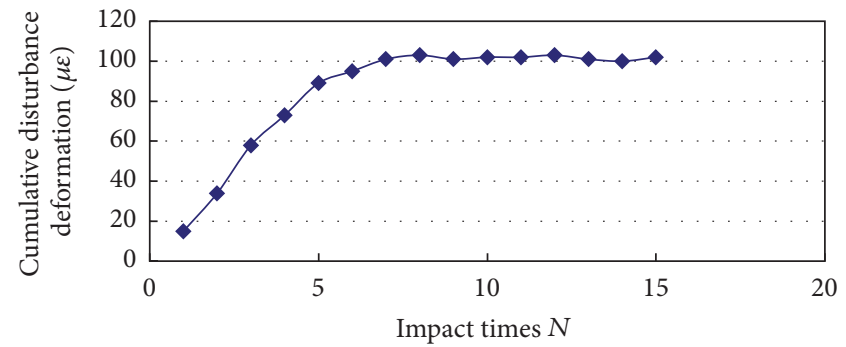

(c) First perturbation

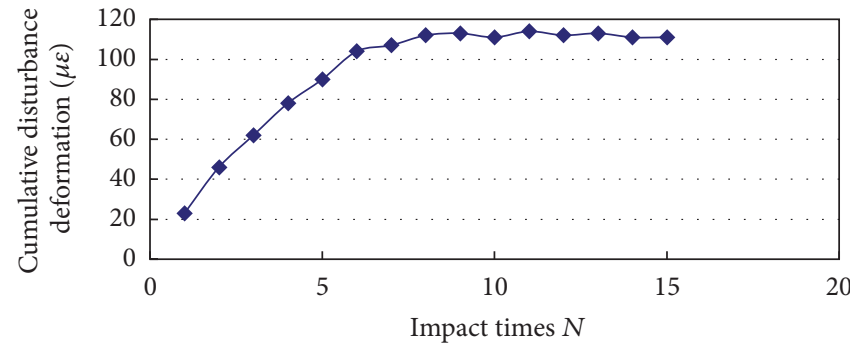

(d) Second perturbation

(2) Level 2 of static stress

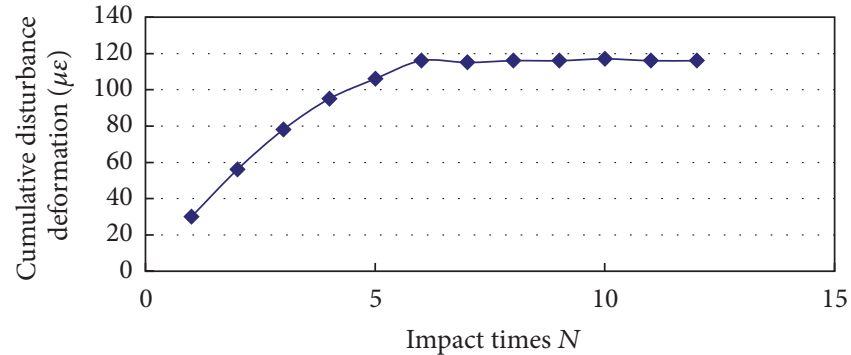

(e) First perturbation

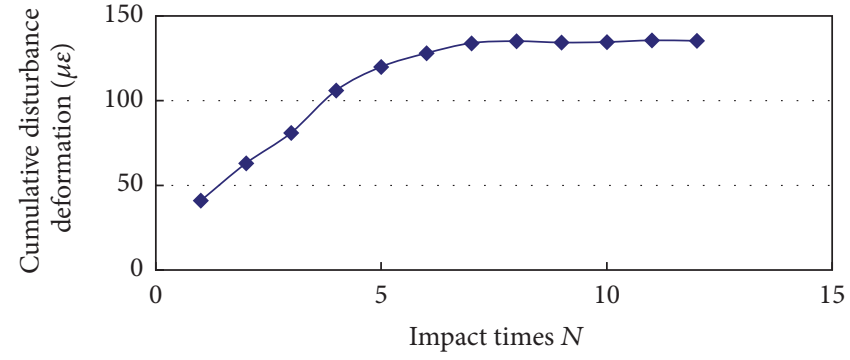

(f) Second perturbation

(3) Level 3 of static stress

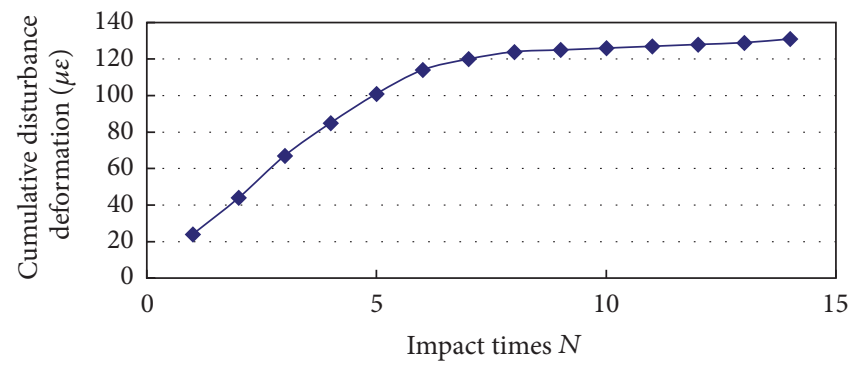

(g) First perturbation

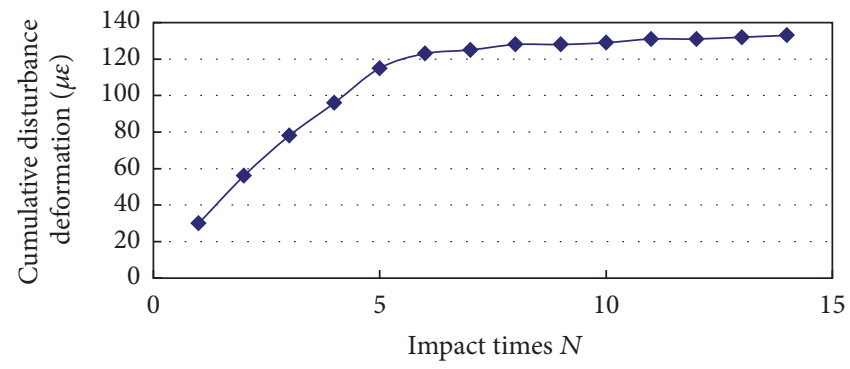

(h) Second perturbation

(4) Level 4 of static stress

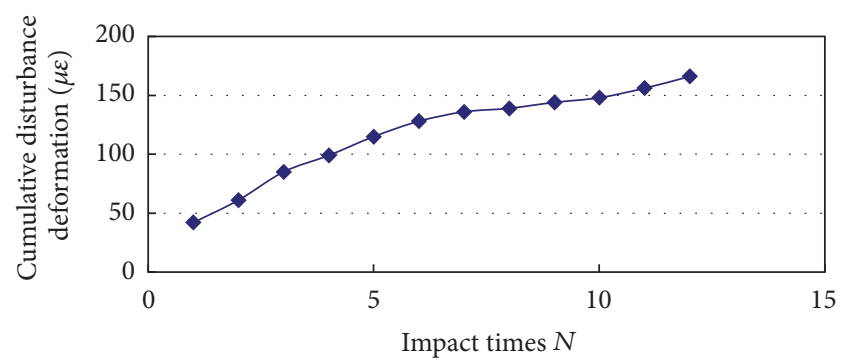

(i) First perturbation

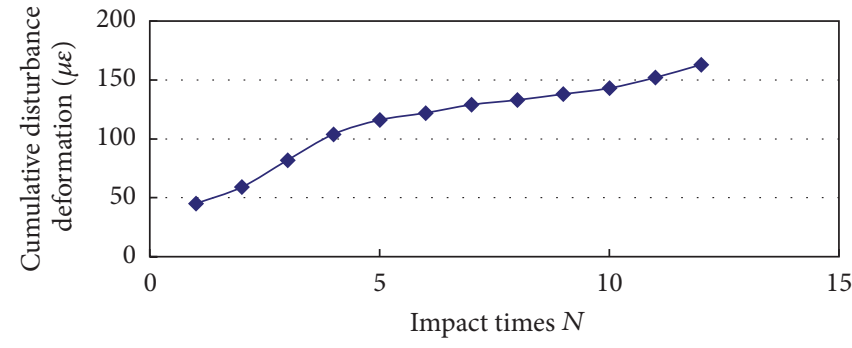

(j) Second perturbation

(5) Level 5 of static stress

FIgURE 9: Continued. 


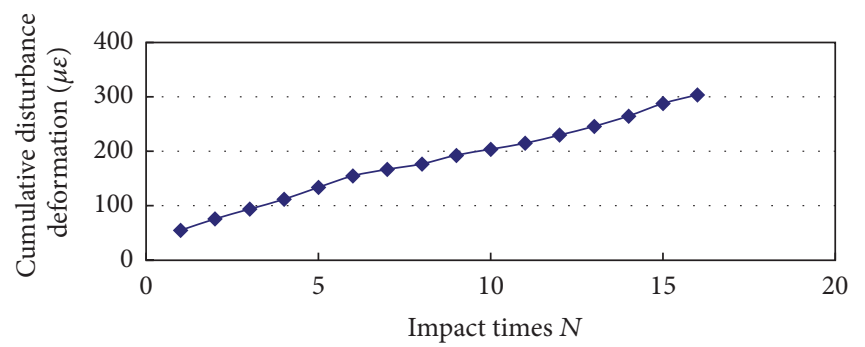

(6) Level 6 of static stress

Figure 9: Relationship curves between specimen cumulative disturbance deformation and impact times under every stress level when the impact loading was $5 \mathrm{~kg}$.

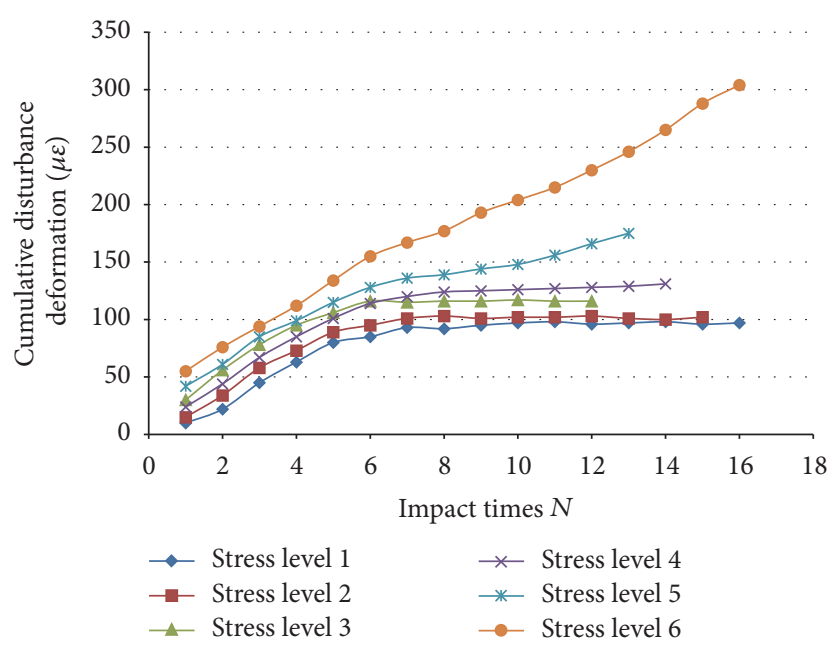

FIGURE 10: Integrated curve when the impact loading was $5 \mathrm{~kg}$.

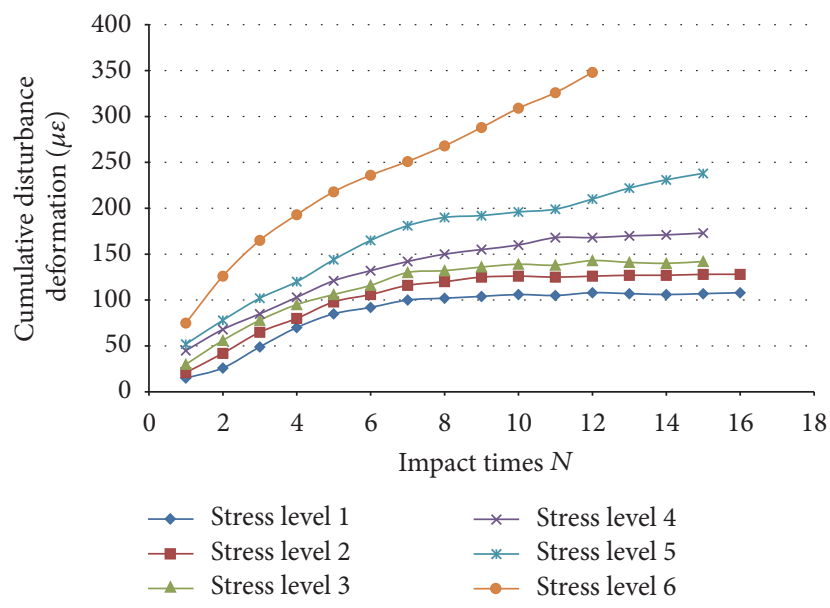

FIGURE 11: Integrated curve when the impact loading was $10 \mathrm{~kg}$.

increase continuously under the low static stress level at the first creep stage; that is, the rocks are insensitive to the external perturbation loading.

Cumulative disturbance deformation is directly proportional to the rock specimen's static stress level. Under the same perturbation strength, the perturbation deformation increased with the increase in the static stress level.

5.2.2. Sustainable Developing Stage of Cumulative Disturbance Deformation. At the fifth static stress level $(70 \mathrm{MPa})$, the applied loading reached $85.4 \%$ of the rock's ultimate strength and $99.3 \%$ of the long-term strength. According to the previous creep experiment, it can be concluded that the rock specimens entered a stable creep stage. The rock's axial total strain was $80 \%$ of the ultimate failure strain before the perturbation. After the perturbation, with the increase in impact times, the cumulative disturbance deformation decreased. In the two groups of experiment, the cumulative disturbance deformation first decreased and then increased. This proves that, with the gradual increase in impact time, the rock's internal injury started to aggravate and transformed from the impact-hardening stage to the injury-failure stage. Moreover, the rock became sensitive to the impact load. When the loading reached the sixth stress level $(79.6 \mathrm{MPa})$, perturbation impact was carried out after two days' creep. The cumulative disturbance deformation generally increased gradually under the linear tendency. At that time, the rock's internal injury further increased, and the development of fracture showed an irreversible growth. The specimens were destroyed after the 16th (cumulative impact load: $3.68 \mathrm{MPa}$ ) and 13th (cumulative impact load: 6.37 MPa) impact tests in the two experiments.

5.3. Effect of Impact Loading Strength on Specimens. A comparative analysis of Figures 6 and 7 shows that the higher the impact strength, the higher the perturbation deformation under the same static stress level impacted by different impact weights. This indicates that, under the creep condition, particularly in the stable creep stage, as the external impact strength increased, the damage inside the rock worsened with heavy perturbation deformation. In the experiment of siltstone specimens impacted by $10 \mathrm{~kg}$ impact weight under the 4th static stress level, in terms of data analysis, the increment of rock creep perturbation deformation did not remain unchanged but increased slightly. However, it was small and basically remained as a single digit. In the later stage, the curve started to shift upwards with a continuous increasing tendency. In the two experiments, the comparative enlarged curves of the perturbation deformation increment 


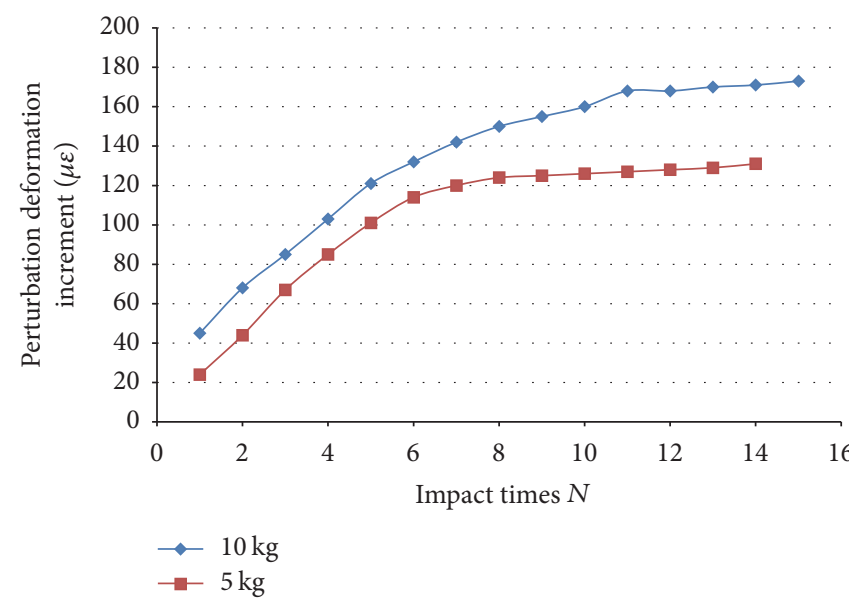

(a) Contrast curve of first perturbation

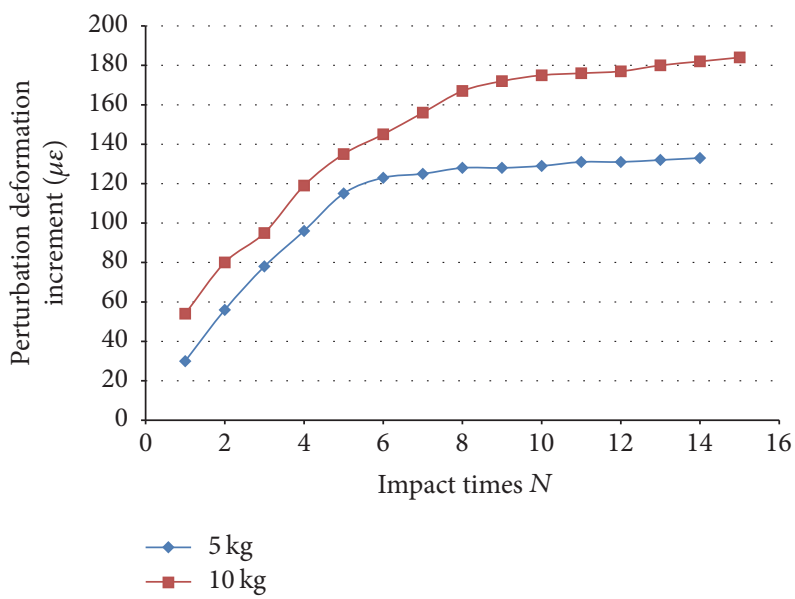

(b) Contrast curve of second perturbation

FIGURE 12: Comparative curves of perturbation deformation increment under the 4th static loading stress.

under the 4th static stress level are shown in Figure 12. By comparison, the differences between the two experiments are clearly illustrated. In the experiment of $5 \mathrm{~kg}$ impact strength, the curve is horizontal with the typical characteristics at the decay stage, whereas under $10 \mathrm{~kg}$ impact strength, the curve slightly increased in the early transitional period from the decay stage to the continuous improvement stage. In the later period, although the creep perturbation deformation slightly increased, it still shows a trend of slow development.

Thus, with the increase in impact strength, the time of the increment line of rock creep perturbation transition from the decay stage to the continuous improving stage becomes short. This causes the following problems: the rock becomes sensitive to external perturbation under a low static stress level, and the damage deformation inside the rock is irreversible. Because of the old experimental specimen and lack of number of impact loadings, the differences in rock perturbation deformation are not obvious. Hence, the above experiments are enough for qualitative studies on rock perturbation response to different impact strengths but are not enough for quantitative studies on rock perturbation response. More experiments should be carried out, and the relationship could be studied using statistics.

5.4. Analysis of Rock Antiperturbation Strength. In terms of the analysis of siltstone specimens' dynamic characteristics under impact loading, the reactions of the creep deformation of specimens to the outer perturbation load are different at different static stress levels. Two areas exist: sensitive area and nonsensitive area. When the static stress is less than a certain value, the effects of outer perturbation load on rock creep deformation are not obvious. As the impact time increases, the increment of perturbation deformation will gradually decrease and eventually remain stable along with rock impact hardening; when the static stress is greater than a certain value, the rock creep is sensitive to outer perturbation. Moreover, with the increase in impact times, the increment of perturbation deformation will increase, and the rock is finally damaged. According to the above characteristics, when the rock creep deformation becomes sensitive to impact loading, the threshold value of the static stress is defined as the antiperturbation strength of rock $\sigma_{r}$, which is the critical stress of sensitive area and nonsensitive area as well. The antiperturbation strength of rock is shown in the variation curve of perturbation deformation increment, that is, the stress value of the inflection point at the decay stage and continuously developing stage. When (stress on rock) $\sigma<$ $\sigma_{r}$, the increment curve of rock perturbation deformation shows a sustained downward trend, and it is not sensitive to perturbation. When $\sigma>\sigma_{r}$, the increment curve of rock perturbation deformation shows a sustainable development status, but it is sensitive to perturbation.

Both experiments tested three siltstone specimens, and the static stress exerted on specimens is shown in Table 4.

According to the analysis of the experimental results, the perturbation deformation increment curve of rock specimen obviously changed from stress level 5. This indicates a transition from the decay phase to the continued development phase. In $10 \mathrm{~kg}$ impact experiments, the experimental curve at stress level 4 shows a slight upward trend, and because the strain is in the single digit level, it is considered that the rock is still in the perturbation deformation increment stage of decay under this stress level. This indicates that the change should start in stress level 5 . The actual stress level 5 in the test is between 69.2 and $70.4 \mathrm{MPa}$, which is about $98.16-99.86 \%$ of the long-term strength and $84.39-85.85 \%$ of the ultimate strength.

According to the experimental analysis, the change in hard siltstone test specimen influenced by external perturbation is not obvious when it is below the long-term strength (flow in the first stage). When the static stress level is close to or even surpasses the long-term strength, the rock specimen in the steady creep state starts to respond apparently under the effect of external perturbation, and the cumulative disturbance deformation shows a sustained development. When the load stress increases further, the impact load would even 
TABLE 4: Static loading stress level of different rock specimens.

\begin{tabular}{|c|c|c|c|c|c|c|c|}
\hline Impact loading & Rock specimen & $\begin{array}{c}\text { Stress level } \\
1 \\
\end{array}$ & $\begin{array}{c}\text { Stress level } \\
2 \\
\end{array}$ & $\begin{array}{c}\text { Stress level } \\
3 \\
\end{array}$ & $\begin{array}{c}\text { Stress level } \\
4 \\
\end{array}$ & $\begin{array}{c}\text { Stress level } \\
5 \\
\end{array}$ & $\begin{array}{c}\text { Stress level } \\
6\end{array}$ \\
\hline \multirow{3}{*}{$5 \mathrm{~kg}$} & 1\# specimen & 56.2 & 58.8 & 64.5 & 66.3 & 70.2 & 79.5 \\
\hline & 2\# specimen & 56.5 & 59.8 & 64.1 & 66.8 & 70 & 79.6 \\
\hline & 3\# specimen & 56.6 & 59.6 & 64.8 & 66.0 & 69.7 & 79.8 \\
\hline \multirow{3}{*}{$10 \mathrm{~kg}$} & 1\# specimen & 56.3 & 59.7 & 64.7 & 66.4 & 69.2 & 79.0 \\
\hline & 2\# specimen & 56.8 & 59.4 & 64.0 & 66.5 & 70.4 & 79.4 \\
\hline & 3\# specimen & 56.5 & 59.5 & 64.2 & 66.5 & 68.8 & 79.6 \\
\hline
\end{tabular}

cause sudden crack damage, similar to the dynamic disaster damage in an underground excavation space in engineering such as mine rockburst and coal wall sheet.

By comprehensive analysis, the antiperturbation and long-term strengths of the hard siltstone specimens are basically the same, $\sigma_{r}=\sigma_{s}$, consistent with the results of previous studies on the moderate intensity of a red sandstone.

\subsection{Practical Significance of Rock's Antiperturbation Strength.} Deep underground rock engineering suffers from complex mechanical conditions in a high in situ stress field. In this field, the surrounding rock mass often demonstrates continuous strong creep characteristics and causes dynamic disasters such as a large deformation and sudden instability under the influence of impact loading. The parameter of rock's antiperturbation strength in this paper is an important index to characterize the influence of external perturbation on the surrounding rock mass. For deep underground rock engineering, the analysis of the perturbation intensity of rock determined in the experiments helps to analyze and determine whether the surrounding rock is in a flow perturbation sensitive area or nonsensitive area as well as the dynamic response to the external perturbation load. Then, the basis for the rational supporting design of deep rock mass engineering can be provided. This has a great significance in engineering practice.

\section{Conclusions}

We conclude the following:

(1) To analyze sedimentary rock's dynamic characteristics in the creep state, a new type of rock creep perturbation experiment system was developed. This equipment has two grades of force-amplification structure which can increase the original gravity load by 60-100 times. It can provide a longtime and constant high static stress. The load infliction of external perturbation loading occurs through the free fall of the impact weights. This new equipment is suitable for carrying out long-term static creep tests and dynamic disturbance tests of rock samples in the creep state.
(2) When a siltstone was influenced by certain external perturbation in the creep process, its perturbation deformation increased irreversibly. The incremental curve of the perturbation deformation generally had two stages: a decay phase and a sustained development phase. When the static stress was up to $\sim 85 \%$ of the rock's ultimate strength and the axial strain was up to $80 \%$ of the ultimate failure strain, the rock became sensitive to impact load and tended to failure.

(3) An increase in the impact strength will aggravate the internal damage in rock mass, induced by a large deformation by the perturbation of the rock. With the increase in impact strength, the cumulative disturbance deformation curve of the rock will be transformed from the decay phase to the sustained development phase in advance, causing the rock to be sensitive to external perturbation in the lower static stress level and decreasing the antiperturbation strength of the rock.

(4) According to the actual measured results, the antiperturbation and long-term strengths of the hard siltstone specimens were basically equivalent: $\sigma_{r}=\sigma_{s}$. Further, the experimental study of the antiperturbation strength of rock is of great practical importance in the supporting design of the stability of deep underground rock engineering in the creep perturbation state.

\section{Conflicts of Interest}

The authors declare that they have no conflicts of interest.

\section{Acknowledgments}

This study was supported by the National Natural Science Foundation of China (nos. 51304127, 51774195, and 51474134), China Postdoctoral Science Foundation (no. 2016M590646), Qingdao Postdoctoral Applied Research Foundation (no. 2016121), Shandong Provincial Natural Science Fund for Distinguished Young Scholars (JQ201612), and Taishan Scholar Talent Team Support Plan for Advantaged and Unique Discipline Areas. 


\section{References}

[1] Y. F. Gao, Q. Z. Fan, X. H. Cui, and Z. L. Fu, Experimental Study on The Perturbation Effect of Rock Rheology, Science Press, Beijing, China, 2007.

[2] C. X. Liu, J. D. He, and M. Z. Zhang, "Long-Term strength test and application of hard fine sandstone in deep site," Journal of Mining and Safety Engineering, vol. 27, no. 4, pp. 581-584, 2010.

[3] L. Jiang, A. Sainoki, H. S. Mitri, N. Ma, H. Liu, and Z. Hao, "Influence of fracture-induced weakening on coal mine gateroad stability," International Journal of Rock Mechanics and Mining Sciences, vol. 88, pp. 307-317, 2016.

[4] Q. B. Zhang and J. Zhao, "A review of dynamic experimental techniques and mechanical behaviour of rock materials," Rock Mechanics and Rock Engineering, vol. 47, no. 4, pp. 1411-1478, 2014.

[5] J. A. Hudson and J. P. Jarrison, Engineering Rock Mechanics, Elsevier Science, Oxford Ltd, 1997.

[6] J. Zhao, H. B. Li, M. B. Wu, and T. J. Li, "Dynamic uniaxial compression tests on granites," International Journal of Rock Mechanics and Mining Sciences, vol. 36, no. 2, pp. 273-277, 1999.

[7] A. Kumar, "The effect of stress rate and temperature on the strength of basalt and granite," Geophysics, vol. 33, no. 3, pp. 501$510,1968$.

[8] S. Demirdag, K. Tufekci, R. Kayacan, H. Yavuz, and R. Altindag, "Dynamic mechanical behavior of some carbonate rocks," International Journal of Rock Mechanics \& Mining Sciences, vol. 47, no. 2, pp. 307-312, 2010.

[9] X. B. Li, T. S. Lok, and J. Zhao, "Dynamic characteristics of granite subjected to intermediate loading rate," Rock Mechanics and Rock Engineering, vol. 38, no. 1, pp. 21-39, 2005.

[10] X. Li, Z. Zhou, T.-S. Lok, L. Hong, and T. Yin, "Innovative testing technique of rock subjected to coupled static and dynamic loads," International Journal of Rock Mechanics and Mining Sciences, vol. 45, no. 5, pp. 739-748, 2008.

[11] Z. L. Zhou, X. B. Li, Z. Ye, and K. W. Liu, "Obtaining constitutive relationship for rate-dependent rock in SHPB Tests," Rock Mechanics and Rock Engineering, vol. 43, no. 6, pp. 697-706, 2010.

[12] Z. Zhou, X. Li, Y. Zou, Y. Jiang, and G. Li, "Dynamic Brazilian tests of granite under coupled static and dynamic loads," Rock Mechanics and Rock Engineering, vol. 47, no. 2, pp. 495-505, 2014.

[13] J. Zhao and H. B. Li, "Experimental determination of dynamic tensile properties of a granite," International Journal of Rock Mechanics and Mining Sciences, vol. 37, no. 5, pp. 861-866, 2000.

[14] S. Okubo, K. Fukui, and J. Kawakami, "Technical note largescale penetration test using a drop hammer," Rock Mechanics and Rock Engineering, vol. 30, no. 2, pp. 113-118, 1997.

[15] D. J. Reddish, L. R. Stace, P. Vanichkobchinda, and D. N. Whittles, "Numerical simulation of the dynamic impact breakage testing of rock," International Journal of Rock Mechanics and Mining Sciences, vol. 42, no. 2, pp. 167-176, 2005.

[16] D. N. Whittles, S. Kingman, I. Lowndes, and K. Jackson, "Laboratory and numerical investigation into the characteristics of rock fragmentation," Minerals Engineering, vol. 19, no. 14, pp. 1418-1429, 2006.

[17] D. Wu, Y.-C. Liu, Z.-X. Zheng, and S. Wang, "Impact Energy Absorption Behavior of Cemented Coal Gangue-Fly Ash Backfill," Geotechnical and Geological Engineering, vol. 34, no. 2, pp. 471-480, 2016.
[18] Y. Gao, W. Huang, G. Qu, B. Wang, X. Cui, and Q. Fan, "Perturbation effect of rock rheology under uniaxial compression," Journal of Central South University, vol. 24, no. 7, pp. 1684-1695, 2017.

[19] M.-R. Shen and H.-J. Chen, "Testing study of long-term strength characteristics of red sandstone," Rock and Soil Mechanics, vol. 32, no. 11, pp. 3301-3305, 2011.

[20] L. Q. Li, W. Y. Xu, and W. Wang, "Estimation of longterm strength for Xiangjiaba sandstone based on creep tests," Engineering Mechanics, vol. 27, no. 11, pp. 127-136, 2010.

[21] Q. S. Liu, W. Gao, and L. Yuan, The Deep Rock Roadways Stability Control Theory and Supporting Technology Application in Coal Mine, Science Press, Beijing, China, 2010.

[22] X. Cui and Z. Fu, "Experimental study on rheology properties and long-term strength of rocks," Chinese Journal of Rock Mechanics and Engineering, vol. 25, no. 5, pp. 1021-1024, 2006.

[23] Y. J. Yang, T. Peng, and G. G. Li, "Study on long term strength of piliar rockmass at yungang grottoes," Chinese Journal of Rock Mechanics and Engineering, vol. 28, no. S2, pp. 3042-3048, 2009.

[24] B. Damjanac and C. Fairhurst, "Evidence for a long-term strength threshold in crystalline rock," Rock Mechanics and Rock Engineering, vol. 43, no. 5, pp. 513-531, 2010. 

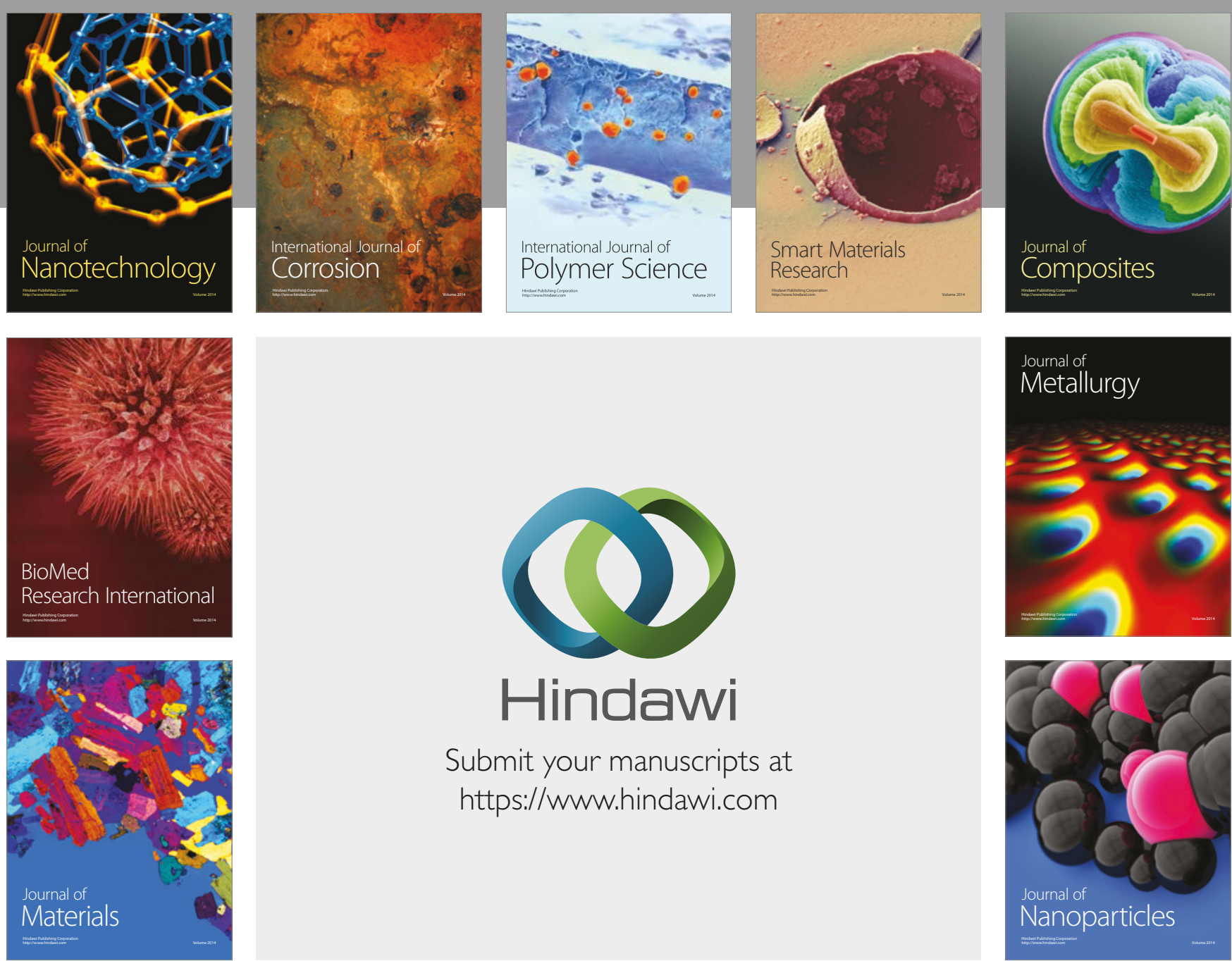

\section{Hindawi}

Submit your manuscripts at

https://www.hindawi.com
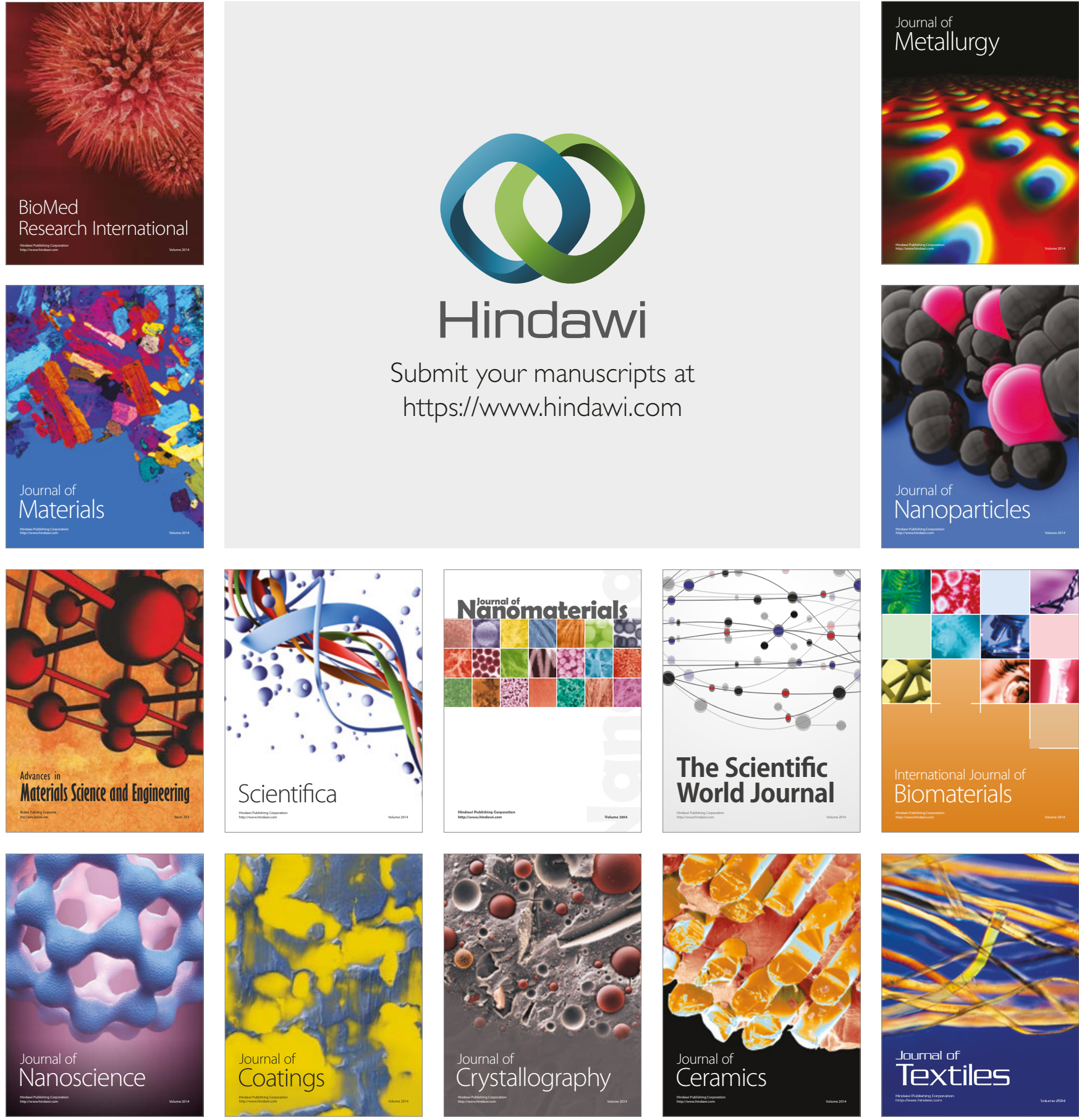

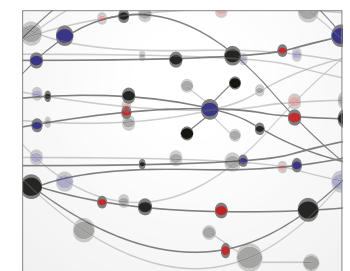

The Scientific World Journal
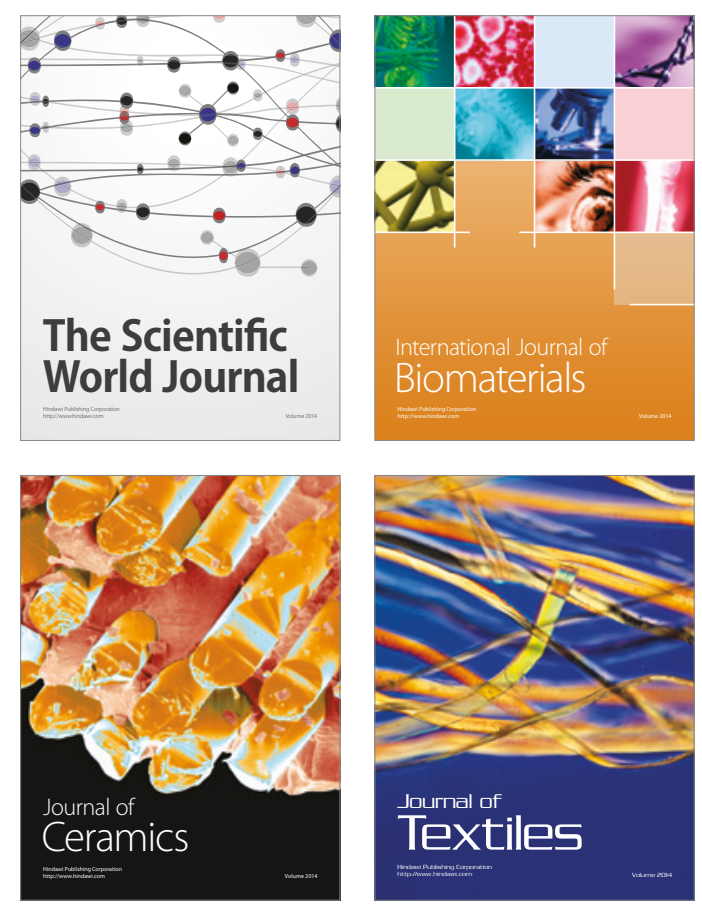